\title{
Induction of Labor in Obese Women -What Should We Know?
}

\author{
Iolanda Ferreira*, Elsa Vasco, Ana Luísa Areia and Paulo Moura \\ Obstetrics a Department, University Center of Coimbra, Portugal
}

*Corresponding author: Iolanda Ferreira, Obstetrics A Department, University Center of Coimbra, Maternidade Doutor Daniel de Matos, R. Miguel Torga, 3030-165; Coimbra, Portugal.

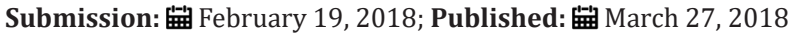

\begin{abstract}
Summary
Maternal obesity is becoming an epidemic in developed countries. This group of women presents an increased risk of labor induction due to the more prevalent associated obstetric comorbidities, such as gestational diabetes and hypertension. On the other hand, they also have an increased rate of failed induction of labor (IOL), which relates directly with increasing body mass index. This leads to higher cesarean section rates and, therefore, higher maternal and neonatal complications. There are few studies comparing the efficacy of different cervical ripening' agents in obese women and none prospective study titrating the dosage of oral misoprostol in induction of labor in those women. The purpose of this mini-review is to alert clinicians to the high failure rate of IOL in obese women and the best way to overcome this issue.
\end{abstract}

Keywords: Obesity; Induction of Labor; Misoprostol

\section{Mini Review}

\section{Maternal obesity worldwide}

Obesity prevalence has been increasing dramatically in the last decades, affecting women in reproductive years and altering obstetric and prenatal outcomes [1].The World Health Organization (WHO) stratifies obesity into three classes: class I (body mass index (BMI) 30-34.9), class II (BMI 35-39.9), and class III (BMI $\geq 40$ ) [2]. Worldwide, approximately 300 million females above the age of 20years are categorized as overweight (BMI 25-29.9kg/m2) or obese (BMI $\geq 30 \mathrm{~kg} / \mathrm{m} 2$ ).

\section{Obesity associated comorbidities and the necessity of labor induction}

Compared to women with normal weight, obese pregnant women have a higher rate of obstetric complications, namely hypertensive complications, gestational diabetes and fetal macrosomia [3,4]. Maternal obesity is also associated with prolonged pregnancy ( $\geq 41$ week's gestation), particularly with BMI of $35 \mathrm{~kg} / \mathrm{m} 2$ or higher [5]. These often lead to labor induction before the due date and consequently a lower pre-induction cervical dilatation in obese women (66\%) [1]. Also, the abovementioned comorbidities are all associated with higher cesarean rates [6]. Therefore, higher rates of IOL and cesarean section (CS) are well described in obese women [7-9]. It is also well known that the degree of obesity is directly associated with induction failure [9].

\section{Data regarding IOL failure in obese women}

In a study regarding prostaglandin IOL, failure of induction and the need of CS occurred with $3.9 \%$ of obese class I and II women and $5.7 \%$ of women in class III obesity [4-10]. In another study this rate was $20.2 \%$ and $24.2 \%$, respectively; also, women with a BMI $40-50 \mathrm{~kg} / \mathrm{m} 2$ had a failed induction rate of $31.6 \%$ and women with a $\mathrm{BMI}>60 \mathrm{~kg} / \mathrm{m} 2$ presented an IOL failure rate as high as $63.2 \%$ [11]. These facts reveal a gap in the knowledge about specific labor induction agents or methods more likely to result in vaginal delivery in obese patients [6]. Unfortunately, only a few studies have specifically compared the outcomes of different induction methods for obese women [9]. The volume of distribution for administered oxytocin/prostaglandins is greater in obese women when compared to lean women [7]. Consequently, obese patients may need more oxytocin or prostaglandins to reach an effective concentration at its myometrial receptors [8].

Suidan et al. compared outcomes for women receiving a $10 \mathrm{mg}$ dinoprostone vaginal insert to those receiving misoprostol $(25 \mu \mathrm{g}$ vaginally or $50 \mu \mathrm{g}$ orally). They adjusted for parity, gestational age, birthweight, and indication for induction, and found that misoprostol had better successful cervical ripening scores and a lower rate of cesarean delivery in obese women. When comparing only oral versus vaginal misoprostol, no differences existed, nor in successful cervical ripening or cesarean delivery. Hence, misoprostol appears to be a more effective induction agent than dinoprostone in obese women. [3] Nevertheless, obese women who receive misoprostol take longer to deliver than non-obese women (by up to 4hours). The 2014 Cochrane review regarding the various methods of induction of labor does not take into consideration titration of the best dosage of misoprostol regarding maternal BMI [12]. Those women are also more likely to require higher use 
of oxytocin than normal weight women, usually 1.5 to 2 times the amount of oxytocin for augmentation of labor used in non-obese

women, and also for longer periods of time (15 to19 h vs.14h) $[1,3,5]$ (Table 1).

Table 1: Correlation between BMI and IOL failure rates.

\begin{tabular}{|c|c|c|c|}
\hline \multicolumn{2}{|c|}{ Correlation Between BMI and IOL Failure Rates } \\
\hline \multirow{2}{*}{ BMI class I } & & Risk factors for IOL failure in obese \\
women & $3,9-20,2 \%$ & $\begin{array}{c}\text { Higher levels of leptin and cholesterol } \\
\text { causing Diminished contractile ability of the } \\
\text { myometrium }\end{array}$ \\
\cline { 1 - 1 } BMI class II & & & Fat deposition in maternal pelvis \\
\hline BMI class III & $5,7-24,2 \%$ & & Fetal macrosomia \\
\cline { 3 - 4 } & & &
\end{tabular}

\section{Possible etiology for induction failure in obese women}

Recent studies suggest that labor in obese women does not respect exactly the standard labor curve, especially in the active stage of labor [13]. Obese women take longer periods to achieve active $6 \mathrm{~cm}$ of dilation. Prolongation of the latent phase correlates directly with maternal weight. In fact, morbidly obese women require more time to reach $6 \mathrm{~cm}$ than women with class I and II obesity $[4,13]$. However, after cervical dilatation of $7 \mathrm{~cm}$, no difference exists between obese and non-obese women.

There are many theories that attempt to determine the reason for the prolonged length of labor in obese women. The leading theory refers to differences in the contractile ability of the myometrium of obese women compared with non-obese women. In obese women without spontaneous labor, it shows decreased contractile function $[3,6]$. However, there does not appear to be a difference in the number of oxytocin receptors at term in obese versus normal weight women. Lepton and cholesterol, a hormone produced by adipose tissue and a lipid, respectively, present higher levels in obese women, and they both decrease the influx of calcium ions into uterine smooth muscle, leading to decreased contractility $[4,5]$. Fat deposition in the maternal pelvis and fetal macrosomia may also be responsible for labor dystocia and lead to CS $[4,14]$. Added to increasing maternal BMI, other factors associated with failure of induction are null parity, low Bishop score, lack of a previous successful vaginal delivery and advanced maternal age. Null parity is a major factor, because obese prime gravitas have labor induced more often than obese multi gravitas, and they are also more likely to end in an emergency section $[11,14]$.

\section{Peri and post-partum complications in obese women}

Obese women are also more likely to have maternal complications after their cesarean delivery, such as chorioamnionitis, thromboembolic events, postpartum infection, and operative complications such as postpartum hemorrhage, incisional extension, or injury to a surrounding tissue $[3,13]$. According to some studies, the neonates of obese women who fail their labor induction have 1.5 to 3 times more neonatal morbidity (respiratory support, antibiotics, and/or transfer to the (NICU) [9]. However, other studies found no difference in neonatal morbidity and showed no increase in cord blood $\mathrm{pH}$ alterations, low Apgar score or incidence of shoulder dystocia [1,6].

\section{Conclusion}

Obstetric providers should be aware of the best induction agents available for obese women. As so, this group should be offered elevated doses of oxytocin, as well as induction with misoprostol rather than dinoprostone. Clinicians should also bear in mind the prolonged labor course in this group and the importance of healthy nutrition and tempered gestational weight gain.

\section{References}

1. Arrowsmith S, Wray S, Quenby S (2011) Maternal obesity and labour complications following induction of labour in prolonged pregnancy. BJOG 118(5): 578-588.

2. Ruhstaller K (2015) Induction of labor in the obese patient. Semin Perinatol 39(6): 437-440.

3. Kobayashi N, Lim BH (2015) Induction of labour and intrapartum care in obese women. Best Pract Res Clin Obstet Gynaecol 29(3): 394-405.

4. Carlson NS, Hernandez TL, Hurt KJ (2015) Parturition dysfunction in obesity: time to target the pathobiology. Reprod Biol Endocrinol 13: 135.

5. Hermann M, Le Ray C, Blondel B, Goffinet F, Zeitlin J (2015) The risk of prelabor and intrapartum cesarean delivery among overweight and obese women: possible preventive actions. Am J Obstet Gynecol 212(2): 241 e1-9.

6. Pevzner L, Powers BL, Rayburn WF, Rumney P, Wing DA (2009) Effects of maternal obesity on duration and outcomes of prostaglandin cervical ripening and labor induction. Obstet Gynecol 114(6): 1315-1321.

7. Hill M, Reed KL, Cohen WR (2015) Oxytocin utilization for labor induction in obese and lean women. J Perinat Med 43(6): 703-706.

8. Gunatilake RP, Smrtka MP, Harris B, Kraus DM, Small MJ, et al.(2013) Predictors of failed trial of labor among women with an extremely obese body mass index. Am J Obstet Gynecol 209(6): 562 e1-e5.

9. Wolfe KB, Rossi RA, Warshak CR (2011) The effect of maternal obesity on the rate of failed induction of labor. Am J Obstet Gynecol 205(2): 128 e1-e7.

10. O'Dwyer V, O'Kelly S, Monaghan B, Rowan A, Farah N, et al.(2013) Maternal obesity and induction of labor. Acta Obstet Gynecol Scand 92(12): $1414-1418$

11. Alfirevic Z, Aflaifel N, Weeks A (2014) Oral misoprostol for induction of labour. Cochrane Database Syst Rev (6): CD001338. 
12. Hirshberg A, Levine LD, Srinivas S (2014) Labor length among overweight and obese women undergoing induction of labor. J Matern Fetal Neonatal Med 27(17): 1771-1775.

13. Goodall PT, Ahn JT, Chapa JB, Hibbard JU (2005) Obesity as a risk factor for failed trial of labor in patients with previous cesarean deliver Am J Obstet Gynecol 192(5): 1423-1426.

14. Grobman WA (2012) Predictors of induction success. Semin Perinatol 36(5): 344-347.
(C) (P) Creative Commons Attribution 4.0

For possible submissions Click Here Submit Article

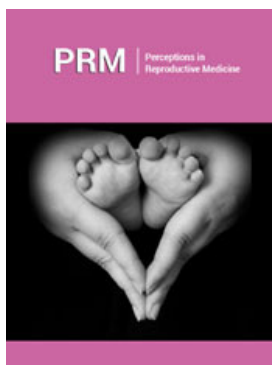

Perceptions in Reproductive Medicine

\section{Benefits of Publishing with us}

- High-level peer review and editorial services

- Freely accessible online immediately upon publication

- Authors retain the copyright to their work

- Licensing it under a Creative Commons license

- Visibility through different online platforms 